\title{
Numerical Study of Flow Separation and Pressure Drop for Flow past Staggered Tube Bundles
}

\author{
Azmahani Sadikin ${ }^{1, a}$ and Norasikin Mat Isa ${ }^{1, b}$ \\ ${ }^{1}$ Centre for Energy and Industrial Environement Studies (CEIES), Faculty of Mechanical \\ Engineering and Manufacturing, Universiti Tun Hussein Onn Malaysia, 86400 Parit Raja, Malaysia \\ aazmah@uthm.edu.my, bsikin@uthm.edu.my
}

Keywords: Flow separation, pressure drop, heat exchanger, staggered bundle, CFD

\begin{abstract}
The vertical single-phase flow was studied on the shell side of a horizontal tube bundle. In the present study, CFX version 14.0 from ANSYS was used to predict the flow regimes in the 19 $\mathrm{mm}$ diameter in staggered configuration with a pitch to diameter ratio of 1.32. The simulations were undertaken to inform on how the fluid flowed within the tube passages. The results show that the tube bundle arrangement in a heat exchanger does effect to the flow separation and re-attachment points. This is consistent with other published data.
\end{abstract}

\section{Introduction}

This study was initiated to support previous studies of kettle reboilers [1-8]. Reboilers are widely used in the process industry for vapour generation. Some developments of horizontal steam generators for nuclear power plants are based on the kettle reboiler design. The kettle reboiler is a shell and tube type heat exchanger usually consisting of a tube bundle arranged on a square-in-line pitch enclosed in a shell for easy cleaning. It also contains a vertical oriented weir of sufficient height to ensure liquid covers the bundle. The heating medium, usually steam, flows in the tubes while the liquid to be partially vapourised is on the shell side. The liquid is usually below the boiling temperature at the bottom-most portion of the bundle. It is heated by natural convection and then by subcooled and saturated boiling as it moves from the bottom to the top. The extent of each regime depends upon the composition of fluid as well as parameters affecting performance, such as type and volume of liquid, operating pressure, heat flux and geometrical parameters. The separation and re-attachment phenonema in the heat exchanger affect the pressure drop and flow pattern in the heat exchangers. Many researchers have constructed flow regime maps to improve the design of shell and tube heat exchangers. Most of these maps were based on visual observations and they were constructed using the maximum superficial gas velocity on the $x$-axis and the maximum superficial liquid velocity on the $y$-axis. Some were constructed using more objective methods, e.g. void fraction transients. The visual observations is used by [6] to study the flow regimes of vertical air-water flow across horizontal tube bundles in a segmental baffled heat exchanger consisting of 39 tubes, $19 \mathrm{~mm}$ in outside diameter, arranged in an in-line configuration with a pitch to diameter ratio of 1.25. Upward flow could be described as either bubbly, intermittent, or spray flow, whereas downward flow could be described as bubbly, stratified and stratified-spray or spray flow. The flow in heat exchanger is said to be in two regions, the separated flow region and the attached flow region [7]. The separated flow region contains the flow between the separation and re-attachment points. The attached flow region contains the flow between the re-attachment and the separation points. The mechanistic model was deduced for each region. The frictional pressure drop is shown to depend on a liquid layer located on the upper portion of the tubes at low gas velocity and on acceleration effects at high gas velocity. Many has observed the flow in heat exchanger in a tube bundle less than $20 \mathrm{~mm}$, but few has reported flow in bundle bigger than $20 \mathrm{~mm}$. In this study, the work of [8] is expanded. The separation angle in the staggered tube bundles are reported. The objective of this paper is to investigate the effect of tube bundle arrangement to the flow separation and re-attachment in the shell side of a shell of heat exchanger. 


\section{Computational Fluid Dynamics}

The flow in a tube passage is assumed to be symmetrical because the geometry and physical conditions causing it are symmetrical and because the flow in any passage between the tubes is likely to be the same as that in any other. So, in the simulations, only a symmetrical half of a flow passage between the tubes is used. The flow is simulated over ten tubes in the flow direction to ensure fully developed flow is achieved. The tube bundle was created in DesignModeler. Two dimensional model was produced in CFX-PRE for the symmetrical half of the water-only bundles. The tube bundle model and grids are shown in Fig. 1. The model was constructed with a grid 0.25 $\mathrm{mm}$ in length. The meshing gave a total of 336,000 nodes and had 1,000,000 elements that consisted of prisms, as shown in Fig. 1(b). The insert picture shows the tube surface inflation was set to rectangular nodes. The tubes were set to solid surfaces with no slip and the east, west, front and back surfaces set to the symmetrical boundary condition. The opening boundary condition at the top of the bundle was set to atmospheric pressure and the inlet boundary was set to a normal velocity of $6 \mathrm{~m} / \mathrm{s}$. An inflation layer of $1.0 \mathrm{~mm}$ thickness and containing 16 layers with an expansion factor of 1.3 was inserted between the tube walls and the bulk fluid to capture the effects near the wall. The simulation was run until the residual of the pressure and velocities were less than 0.00001 .

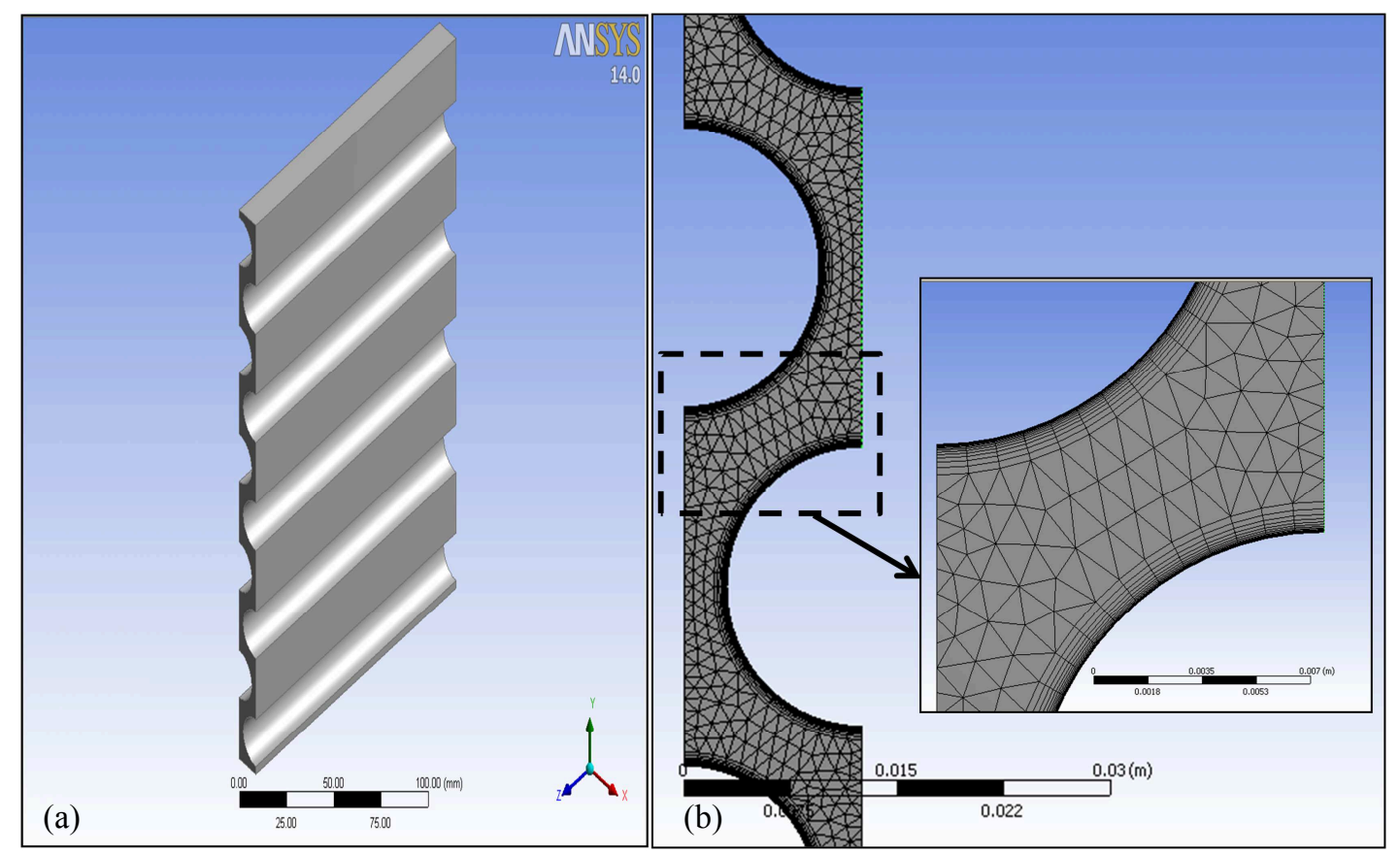

Figure 1: The model (a) $19 \mathrm{~mm}$ in diameter staggered bundle (b) the grids and inflation

\section{Results and Discussion}

Fig. 2(a) shows the velocity vectors for the bundle. The fluid flow is high in the main stream and follow a more torturous path. As the fluid flows past the tubes, which was set to no slip at the wall, the fluid decelerates near the tube surface and creates a thin layer, called the boundary layer, due to viscous effects. The flow is attached to the tube surface until the formation of a wake, evident to the rear of the tube, where some of the fluid is flowing backward against the main flow. The maximum velocity occurs at $\theta=90^{\circ}$. Near $\theta=180^{\circ}$, the velocity is at a minimum or zero. This is where the circulation happens, see Fig. 2(b). The flow re-attaches at the front of the tube. 


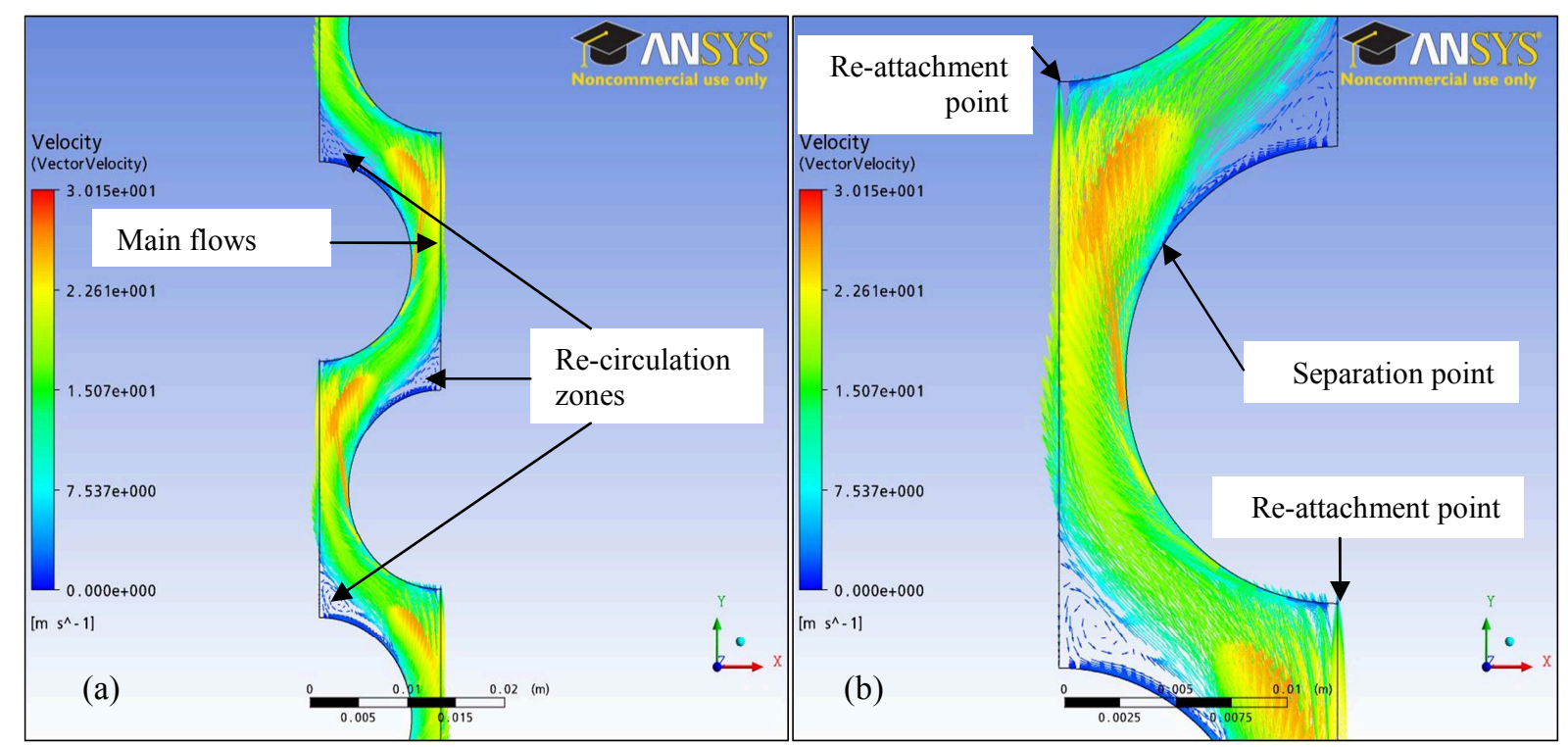

Figure 2: (a) Main stream flow and re-circulation zone between the tubes (b) Separation point and re-attachment point

Flow separation occurs when the shear stress is zero as shown in Fig. 3. The flow separates at $\theta_{S}=$ $116^{\circ}$. The flow re-attaches at the tube front, as seen in the Fig. 2(a) and Fig. 2(b), i.e. $\theta_{R}=0^{\circ}$.

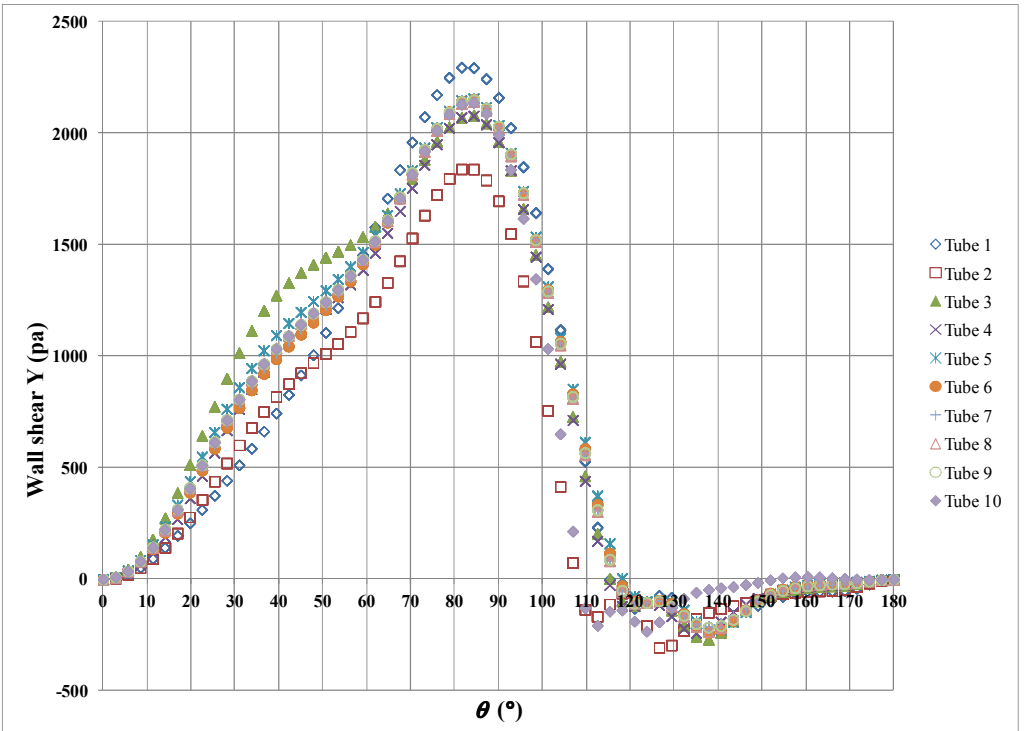

Figure 3: Wall shear $\mathrm{Y}$ distribution around the tube surface at various angles on the tubes.

Separation flow is at $\theta_{S}=116^{\circ}$ and re-attachment flow is at $\theta_{R}=0^{\circ}$

The pressure drop is largest on the first row of tubes, as seen in Fig. 4. This is caused by fluid acceleration due to the reduction in flow area. The staggered alignment gives further reductions in pressure due acceleration and separation from the tube walls. As a result, the friction pressure loss is higher in the staggered tube bundle arrangement. As expected, the pressure is shown to gradually decrease and increase as the flow moves around the tubes. The pressure drop in these tubes is caused by the reduction in flow area as the flow moves towards the minimum gap. Pressure recovery occurs as the flow separates from the tube just after the minimum gap and expands to reattach to the next tube. There is a net pressure drop across each tube due to friction. 


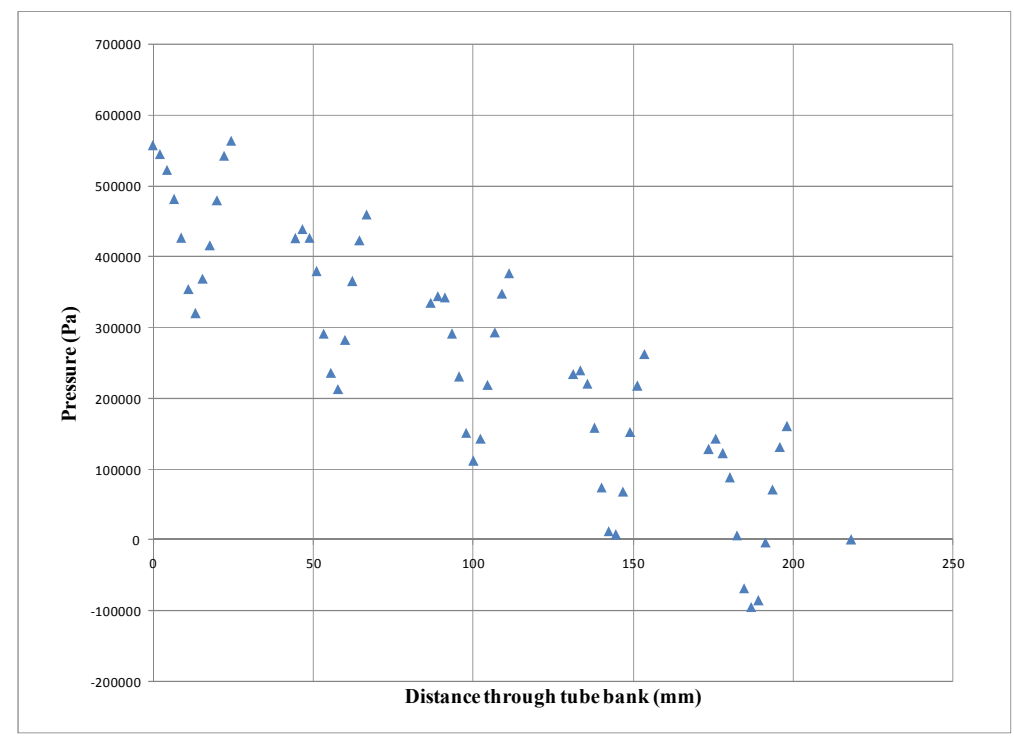

Figure 4: Variation of pressure with distance through the tube banks

The pressure distribution around the tubes for the staggered tube bundle is shown in Fig. 5. The pressure is highest at $\theta=0^{\circ}$ and decreases as the flow travels from $\theta=0^{\circ}$ to $\theta=90^{\circ}$, where the pressure reaches a minimum as the maximum velocity occurs at $\theta=90^{\circ}$, see Fig. 2(b) and Fig. 3 . The pressure recovers a little up to the separation point at $\theta_{S}=115^{\circ}$ where the flow separates from the tube surface. The wake region at the rear of the tube will cause a low pressure region due to turbulent dissipation. The drag force results from boundary layer separation, the pressure on the rear half of each tube being considerably less than that on the front half $\left(\theta=90^{\circ}\right.$ to $\left.\theta=180^{\circ}\right)$. Overall, the loss of energy in the direction of flow is shown. As the fluid flows from $\theta=0^{\circ}$ to $\theta=90^{\circ}$, the pressure falls. The increase in pressure in the direction of flow along the rear half of the tube from $\theta$ $=90^{\circ}$ to $\theta=180^{\circ}$ is seen in the figure for all tubes.

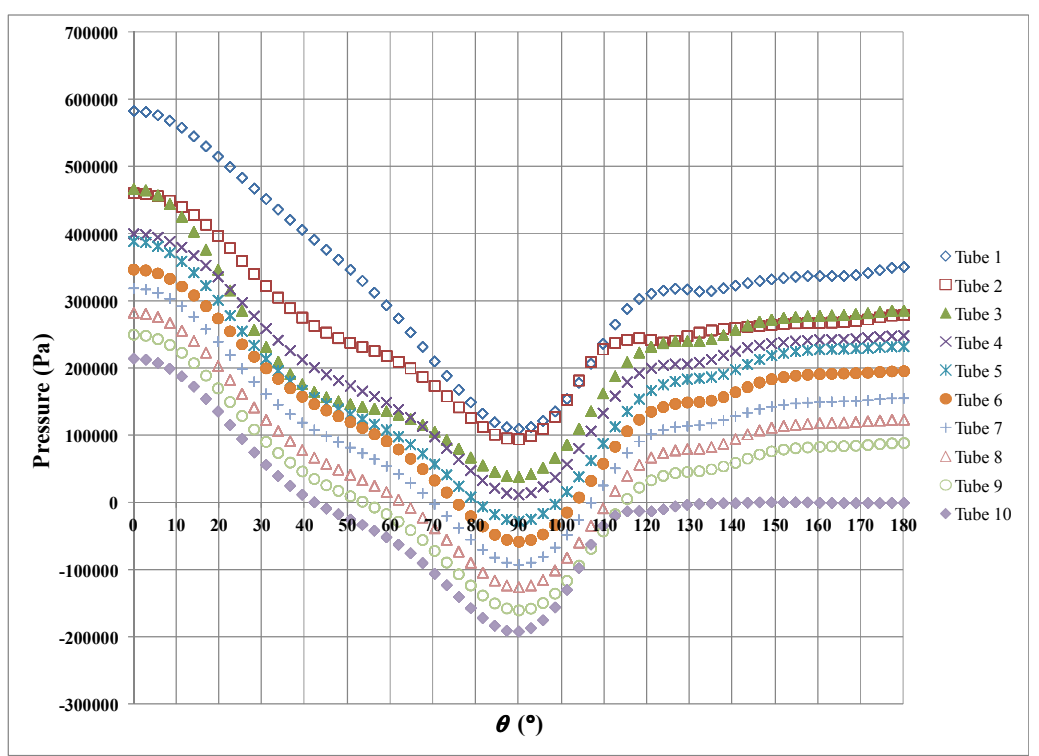

Figure 5: Pressure distribution around the tubes surface at various angles on the tubes

\section{Comparisons with previous work}

The velocity vectors for staggered arrangement are different when compared to in-line bundles in [8]. The separation and re-attachment flows are different too for both arrangments. Re-circulation flow is formed in every vertical minimum gap between the tubes for inline bundle, whereas for the staggered bundle, the re-circulation flow is formed at the top of the tubes, as shown in Fig. 2(b). 
The water creates a significantly bigger re-circulation zone for both in-line bundles [8], in comparison to the staggered bundle, where the fluid only creates a small re-circulation zone. However, the in-line and staggered arrangements both have a high velocity in the minimum gaps where the water flow is not separated from the walls. Flow separation is delayed in the staggered arrangement, when compared to inline bundles in [8] where the separation point is at $\theta_{S}=116^{\circ}$ and the re-attachment point occurs at $\theta_{R}=0^{\circ}$ as shown in Fig. 3.

\section{Conclusion}

The re-attachment angle in single-phase flow suggests it is smaller than two-phase flow, whereas the separation angle in single-phase flow suggests that it is larger than two-phase flow. The reattachment and separation angles are important because they control the size of the form loss and drag force created by the wakes at the rear of the tubes. The re-attachment point is at $\theta_{R}=0^{\circ}$ and separation point is at $\theta_{S}=90^{\circ}$ for staggered bundle. These values are chosen to best fit to the data, supported by the single-phase CFD simulations presented in this paper. Therefore, prediction of flow separation for other working fluid and geometry is warranted.

\section{Acknowledgement}

The author would like to thank the Universiti Tun Hussien Onn Malaysia (UTHM) and Ministry of Higher Education of Malaysia (MoHE) for financial support. This work was also supported by Research Acculturation Grant Scheme (RAGS) (No. R028).

\section{References}

[1] Kumar S., 2003, Recirculation model of kettle reboiler, International Journal of Heat and Mass Transfer, 46(15), 2899-2909.

[2] Jensen M.K., 1998, Model for the recirculating flow in a kettle reboiler, in: Proceedings, Houston, TX, USA, Publ by AIChE, New York, NY, USA.

[3] Bamardouf K.H., McNeil D.A., Experimental and numerical investigation of two-phase pressure drop in vertical cross-flow over a horizontal tube bundle, Journal of Applied Thermal Engineering, 29, (2009) 1356-1365.

[4] Sadikin A., McNeil D.A., Bamardouf K.H., 2010, Two-phase flow on the shell side of a shell and tube heat exchanger, In: Proc. of the $14^{\text {th }}$ Int. Heat Transfer Conference, August 8-13, Washington DC, USA.

[5] McNeil D.A., Bamardouf K.H., Burnside B.M., Almeshaal M., 2010, Investigation of flow phenomena in a kettle reboiler. International Journal of Heat and Mass Transfer, 53, 836-848.

[6] Grant I.D.R., Chisholm D., 1979, Two-phase flow on the shell side of a segmentally baffled shell-and-tube heat exchanger, Journal of heat transfer, Transaction ASME, 101(1), 38-42.

[7] McNeil D.A., Sadikin A., Bamardouf K.H., 2012, A mechanistic analysis of shell-side twophase flow in an idealized in-line tube bundle, International Journal of Multiphase Flow, 45, 53-69.

[8] Sadikin A., Mat Isa N., 2014, Flow separation prediction in a single-phase flow in an inline tube bundles, Applied Mechanics and Materials, Vols. 465-466, 608-612 